\title{
ANALISIS JALINAN JALAN (WEAVING AREA) PADA RUAS JALAN YOS SOEDARSO-KINIBALU DI BUNDARAN BESAR PALANGKA RAYA
}

\section{NIRWANA PUSPASARI ${ }^{1)}$ DAN AHMAT SOLIKIN ${ }^{2)}$}

\author{
1) Dosen Program Studi Teknik Sipil; ${ }^{2)}$ Mahasiswa Program Studi Teknik Sipil, Fakultas Teknik \\ Universitas Muhammadiyah Palangkaraya
}

\begin{abstract}
The aim of this study is to determine the performance of weaving area and the volume of traffic at this time. The study of this weaving area is in the form of primary and secondary data collection. The primary data included the data of traffic flow volume and side constraints. The secondary data included the data on the number of population and geometric data on the part of weaving area at the big round. The analysis was calculated based on the method of Indonesian Highway Capacity Manual 1997, which resulted in the form of volume, capacity, degree of saturation, delays and queues opportunities.

From the result of the analysis, it was found that the volume at peak hours in the morning, afternoon, and evening respectively; $\left(Q_{\text {TOTAL }}\right)=2420.07 \mathrm{smp} /$ hour $\left(Q_{\text {TOTAL }}\right)=2776.13 \mathrm{smp} / \mathrm{hour}$ and $\left(Q_{\text {TOTAL }}\right)=2337.17 \mathrm{smp} /$ hour. Whereas the performance on the part of weaving area of daily traffic average at peak hours in the morning can actually capacity $(C)=3481.848 \mathrm{smp} / \mathrm{h}$, the degree of saturation $D S=0.695$, delay braided section $(D T)=3.799$ sec/smp, and opportunities queue braided section $(Q p \%)=$ lower limit/minimum of $12.12 \%$, and the upper limit/maximum of $28.18 \%$. On the daily traffic average at peak hours during the day obtained the capacity actually $(C)=3495.967 \mathrm{smp} / \mathrm{h}$, the degree of saturation $D S=0692$, delay part of weaving area $(D T)=3,766 \mathrm{det} / \mathrm{smp}$, and opportunities queue section weaving area $(Q p \%)=$ lower limit/minimum of $11.99 \%$, and the upper limit/maximum of $27.89 \%$. On the daily traffic, the average at peak hours in the afternoon, the accually capacity can be obtained $(C)=3593.639 \mathrm{smp} / \mathrm{h}$, the degree of saturation $D S=0673$, delay part weaving area $(D T)=3,546 \mathrm{det} / \mathrm{smp}$, and opportunities queue section weaving area $(Q p \%)=$ lower limit/minimum $11.16 \%$, and the upper limit/maximum of 25.95\%. Based on the analysis, the results obtained Degree of Saturation (DS) to all parts of weaving area is less than 0.75 the terms set forth in MKJI, 1997 so that each hour of the peak that occurred in parts of weaving area on Yos Sudarso-Kinibalu street is still qualify.
\end{abstract}

Keywords: capacity, traffic volume, degree of saturation, delay, connect roads and round abouts

\section{ABSTRAK}

Penelitian ini bertujuan untuk mengetahui kinerja bagian jalinan (weaving area) dan volume lalu lintas saat ini. Penelitian yang dilakukan pada bagian jalinan ini yaitu dengan pengumpulan data primer dan sekunder. Data primer meliputi data volume arus lalu lintas dan hambatan samping. Sedangkan data sekunder meliputi data jumlah penduduk dan data geometrik pada bagian jalinan di bundaran tersebut. Dalam melakukan analisis, perhitungan berdasarkan metode dari Manual Kapasitas Jalan Indonesia 1997, yang mana akan dihasilkan berupa volume, kapasitas, derajat kejenuhan, tundaan dan peluang antrian.

Hasil analisis mendapatkan volume pada jam puncak pagi, siang, dan sore berturut-turut; $\left(Q_{\text {TOTAL }}\right)=2420,07 \mathrm{smp} / \mathrm{jam},\left(\mathrm{Q}_{\text {TOTAL }}\right)=2776,13 \mathrm{smp} / \mathrm{jam}$ dan $\left(\mathrm{Q}_{\text {TOTAL }}\right)=2337,17 \mathrm{smp} / \mathrm{jam}$. Sedangkan kinerja bagian jalinan pada lalu lintas harian rata-rata pada jam puncak pagi hari didapat kapasitas sesungguhnya $(C)=3481,848 \mathrm{smp} / \mathrm{jam}$, derajat kejenuhan $\mathrm{DS}=0,695$, tundaan bagian jalinan $(\mathrm{DT})=3,799 \mathrm{det} / \mathrm{smp}$, dan peluang antrian bagian jalinan $(\mathrm{Qp} \%)=$ batas bawah/minimum sebesar 12,12\%, dan pada batas atas/maksimum sebesar $28,18 \%$. Lalu lintas harian rata-rata pada jam puncak siang hari didapatkan kapasitas sesungguhnya $(C)=3495.967 \mathrm{smp} / \mathrm{jam}$, derajat kejenuhan $\mathrm{DS}=0.692$, tundaan bagian jalinan $(\mathrm{DT})=3.766 \mathrm{det} / \mathrm{smp}$, dan peluang antrian bagian jalinan $(\mathrm{Qp} \%)=$ batas bawah $/ \mathrm{minimum}$ sebesar $11.99 \%$, dan pada batas atas/maksimum sebesar $27.89 \%$. Pada lalu lintas harian rata-rata pada jam puncak sore hari di dapat kapasitas sesungguhnya $(C)=3593.639 \mathrm{smp} / \mathrm{jam}$, derajat kejenuhan $\mathrm{DS}=0.673$, tundaan bagian jalinan $(\mathrm{DT})=3.546 \mathrm{det} / \mathrm{smp}$, dan peluang antrian bagian jalinan $(\mathrm{Qp} \%)=$ batas bawah/minimum sebesar $11.16 \%$, dan pada batas atas/maksimum sebesar $25.95 \%$. Hasil analisa memperoleh Derajat Kejenuhan (Ds) untuk semua bagian jalinan kurang dari 0,75 syarat yang sudah ditetapkan dalam MKJI, 1997 sehingga dari masing-masing jam puncak yang terjadi pada bagian jalinan pada segmen jalan Yos Soedarso-Kinibalu masih memenuhi syarat.

Kata kunci : kapasitas $(C)$, volume lalu lintas $(Q)$, derajat kejenuhan (Ds), tundaan (Dt), jalinan jalan dan bundaran 


\section{PENDAHULUAN}

\section{Latar Belakang}

Kota Palangka Raya merupakan ibu kota Kalimantan Tengah yang terletak pada titik koordinat 2012'36"LS 11355'12"BT. Dengan banyaknya kemacetan lalu lintas di Jakarta, pada akhir bulan Juli dan awal Agustus 2010 muncul beberapa wacana untuk memindahkan ibu kota Indonesia ke Palangka Raya. Dengan adanya wacana tersebut pertumbuhan penduduk dan roda perekonomian Kota Palangka Raya sangat meningkat, dengan meningkatnya jumlah penduduk tersebut maka permintaan akan transportasi juga kian meningkat, sehingga diperlukan sarana transportasi yang lebih baik. Seperti diketahui bahwa sekarang ini banyak sekali alat transportasi yang dapat digunakan, namun alat transportasi darat yang lebih dominan. Dengan meningkatnya arus lalu lintas sedangkan penyediaan prasarana yang kecil akan menimbulkan ketidak seimbangan dan mengakibatkan kemacetan yang berdampak pada lamanya perjalanan sehingga menimbulkan pemborosan secara material.

Permasalahan simpul jalan juga adalah kemacetan. Hal ini disebabkan adanya konflik kendaraan yang terjadi pada dua kendaraan atau lebih yang menggunakan ruang maupun waktu yang sama dalam melakukan pergerakan. Pada bundaran besar di kota Palangka Raya terdapat persimpangan 6 lengan yaitu persimpangan $\mathrm{J}$. Yos Soedarso, Jl. Kinibalu, Jl. Tjilik Riwut, Jl. Brigjen Katamso, JI. DI. Panjaitan dan JI. Imam Bonjol. Pada salah satu persimpangan tersebut terdapat volume jalinan arus yang cukup besar, yaitu pada daerah jalinan (weaving area) Imam Bonjol-Yos Sudarso.
Dari pengamatan daerah jalinan Yos Sudarso-Kinibalu di Bundaran Besar Kota Palangka Raya, terjadi perlambatan arus kendaraan yang bisa menyebabkan kemacetan pada daerah jalinan tersebut. Hal ini disebabkan karena pada bagian jalinan (weaving section) tersebut, terjadi jalinan arus lalu lintas yang cukup besar dengan lebar area weaving yang sempit, dibandingkan pada area weaving yang lainnya yang ada di bundaran besar Palangka Raya.

Dalam menganalisa kinerja suatu weaving area pada suatu bundaran, perlu menghitung volume lalu lintas dan kapasitas pada daerah jalinan (weaving). Hal ini penting dilakukan untuk mengetahui tingkat kinerja weaving area yang akan di analisa.

Kapasitas weaving didefinisikan sebagai arus lalu lintas total pada saat bagian jalinan (weaving section) yang pertama mencapai kapasitasnya (MKJI, 1997). Kapasitas weaving dipengaruhi oleh konfigurasi, jumlah lajur, kecepatan arus bebas, panjang dan lebar jalinan dan proporsi total arus yang terjalin ( $\mathrm{HCM}$, 2000).

Dari pengamatan daerah jalinan Yos Soedarso-Kinibalu di Bundaran Besar kota Palangka Raya, pada saat jam puncak terjadi perlambatan kendaraan yang bisa menyebabkan kemacetan pada daerah jalinan tersebut. Hal ini disebabkan karena pada bagian jalinan (weaving section) tersebut, terjadi jalinan arus lalu lintas yang cukup besar dengan lebar area weaving yang sempit, dibandingkan pada area weaving yang lainnya yang ada di bundaran besar Palangka Raya. 
Pada bundaran besar Palangka Raya terdapat persimpangan 6 lengan yaitu persimpangan Jl. Yos Soedarso, Jl. Kinibalu, Jl. Tjilik Riwut, JI. Brigjen Katamso, Jl. DI. Panjaitan dan Jl. Imam Bonjol. Pada salah satu persimpangan tersebut terjadi tundaan yang disebabkan oleh volume lalu lintas yang besar. Yang mana terjadi pertemuan arus dari jalan Imam Bonjol maupun persimpangan jalan yang lainnya yang bertemu dengan arus lalu lintas dari jalan Yos Soedarso.

Pada arus lalu lintas dari jalan Imam Bonjol terdapat kendaraan dari Banjarmasin maupun masyarakat kota Palangka Raya yang akan menuju jalan Kinibalu maupun jalan Tjilik Riwut yang mana pada jalan Kinibalu terdapat pintu masuk Palangka Raya Mall (Palma), sedangkan pada arus lalu lintas dari jalan Yos Soedarso terdapat kendaraan yang akan pulang dari Mall Hypermart, Perguruan Tinggi Universitas Palangka Raya maupun kendaraan yang akan menuju daerah jalan Kinibalu maupun jalan di persimpangan bundaran besar Palangka Raya. Dari pertemuan dua ruas jalan tersebut terjadilah konflik arus lalu lintas terutama pada konflik weaving yang mengakibatkan tundaan dan bahkan kecelakaan, sehingga dianggap perlu untuk ditinjau lebih lanjut. Karena permasalahan itu maka perlu dilakukan penelitian mengenai Analisis Jalinan Jalan (Weaving Area) pada Ruas Jalan Yos Soedarso-Kinibalu di Bundaran Besar Palangka Raya.

\section{Rumusan Masalah}

Berdasarkan latar belakang yang telah di kemukakan diatas maka di buat rumusan masalah sebagai berikut:
1. Berapa volume lalu lintas pada bagian jalinan (weaving section) bundaran besar Palangka Raya pada segmen jalan Yos SoedarsoKinibalu?

2. Bagaimanakah kinerja bagian jalinan bundaran besar Palangka Raya pada segmen jalan Yos Soedarso-Kinibalu?

\section{Tujuan Penelitian}

Adapun tujuan dari penelitian ini adalah:

1. Untuk mengetahui volume lalu lintas pada bagian jalinan (weaving section) bundaran besar Palangka Raya pada segmen jalan Yos Soedarso-Kinibalu.

2. Untuk mengetahui kinerja bagian jalinan bundaran besar Palangka Raya pada segmen jalan Yos Soedarso-Kinibalu.

\section{METODOLOGI}

Penelitian ini dilakukan dengan melakukan survey lapangan terhadap kondisi geometrik dan arus lalu lintas, sehingga dengan data geometrik jalan dan bundaran tersebut dapat dilakukan analisis bagian jalan terutama pada jalinan Bundaran yang disesuaikan dengan bagian jalan sesuai Manual Kapasitas Jalan Indonesia (MKJI).

\section{Alat dan Bahan}

Adapun alat yang digunakan dalam penelitian ini adalah:

1. 2 buah Camera Handycam;

2. Meteran panjang untuk mengukur Geometrik jalan;

3. Payung 1 buah untuk melindungi alat dari panas maupun hujan. 


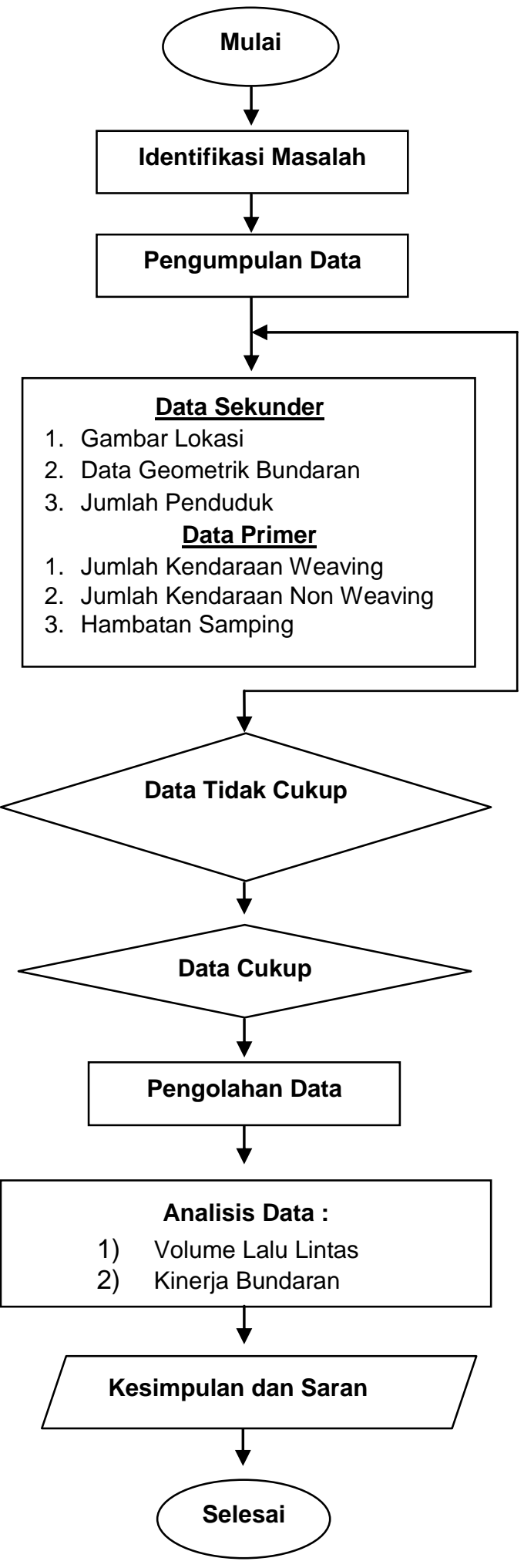

Gambar 1. Diagram Alir Penelitian

\section{Teknik Pengumpulan Data}

Teknik pengambilan data yang dilakukan pada saat survey lapangan adalah pada persimpangan bundaran besar, dilakukan beberapa kali pengamatan, sebagai berikut:

a. Pada lajur persimpangan, dilakukan pencatatan 2 gerakan arah kendaraan yang melalui jalan tersebut, yaitu gerakan weaving dan gerakan non weaving;

b. Pada saat pengamatan ditempatkan 1 buah camera video (handycam) untuk menghitung gerakan arus lalu lintas.

\section{Data Primer}

Data primer yang dikumpulkan berupa volume kendaraan, lebar jalan, gometrik simpang dan kelengkapan prasarana jalan. Data LHR diperoleh dengan melakukan survay lapangan selama 1 (satu) minggu untuk kemudian dinyatakan ke dalam satuan mobil penumpang (smp). Dengan melakukan survay tersebut akan diketahui jam puncak dan data pada jam puncak tersebutlah yang diambil untuk perhitungan.

\section{Data Sekunder}

Data sekunder yang diperlukan adalah:

a. Denah persimpangan Bundaran Besar Kota Palangka Raya.

b. Data jumlah penduduk Kota Palangka Raya

Tabel 1. Rasio volume weaving area dan kendaraan tak bermotor dengan jam puncak lalu lintas harian rata-rata

\begin{tabular}{|c|c|c|c|c|c|c|}
\hline $\begin{array}{c}\text { Jam } \\
\text { Puncak }\end{array}$ & \multicolumn{2}{|c|}{ QTOTAL } & QW & QNW & PW & PUM \\
\hline \multirow{2}{*}{ Pagi } & um & 19 & \multirow{2}{*}{1335,97} & 1084,1 & 0,55 & 0,008 \\
\cline { 2 - 7 } & Qtot & 2420,07 & & & & \\
\hline \multirow{2}{*}{ Siang } & um & 12.33 & \multirow{2}{*}{1477,90} & 1298,23 & 0,53 & 0,004 \\
\cline { 2 - 7 } & Qtot & 2776,13 & & & & \\
\hline \multirow{2}{*}{ Sore } & um & 39.67 & \multirow{2}{*}{1203,27} & 1133,9 & 0,51 & 0,017 \\
\cline { 2 - 4 } & Qtot & 2337,17 & & & & \\
\hline
\end{tabular}




\section{Kapasitas Bagian Jalinan Bundaran Kapasitas Dasar (Co)}

Nilai kapasitas dasar (Co) dipengaruhi oleh kondisi geometrik dari bundaran.

Berdasarkan rumus 2.1 nilai kapasitas dasar dapat diketahui sebagai berikut:

1) Perhitungan kapasitas dasar (Co) jam puncak pada pagi hari

a) Nilai factor $W_{W}$

$$
=135 \times 9,0^{1,3}=2348,815
$$

b) Nilai faktor $W_{E} W_{W}$

$$
=(1+0,1666)^{1,5}=3,809
$$

c) Nilai faktor $P_{w}$

$$
=(1-0,55 / 3)^{0,5}=0,57
$$

d) Nilai faktor $W_{E} / L_{W}$

$$
\begin{aligned}
& =(1+0,1158)^{-1,8}=0,821 \\
\text { Co } & =2348,815 \times 3,809 \times 0,57 \times 0.821
\end{aligned}
$$

2) Perhitungan kapasitas dasar (Co) jam puncak pada siang hari

a) Nilai faktor WW

$$
=135 \times 9.0^{1,3}=2348,815
$$

b) Nilai faktor $W_{E} / \mathrm{WW}$

$$
=(1+0,1666)^{1,5}=3,809
$$

c) Nilai faktor PW

$$
=(1-0,53 / 3)^{0,5}=0,58
$$

d) Nilai faktor WE/LW

$$
=(1+0,1158)^{-1,8}=0,821
$$

Co $=2348,815 \times 3,809 \times 0,57 \times 0,821$

$$
=4257,974 \mathrm{smp} / \mathrm{jam}
$$

3) Perhitungan kapasitas dasar (Co) jam puncak pada sore hari

a) Nilai faktor WW

$$
=135 \times 9,0^{1,3}=2348,815
$$

b) Nilai faktor WE/WW

$$
=(1+0,1666)^{1,5}=3,809
$$

c) Nilai faktor PW

$$
=(1-0,51 / 3)^{0,5}=0,59
$$

d) Nilai faktor $W_{E} / \mathrm{LW}$

$$
\begin{aligned}
& =(1+0,1158)^{-1,8}=0,821 \\
\text { Co } & =2348,815 \times 3,809 \times 0,57 \times 0,821 \\
& =4316,787 \mathrm{smp} / \mathrm{jam}
\end{aligned}
$$

\section{Kapasitas Sesungguhnya (C)}

Untuk menghitung besarnya kapasitas sesungguhnya digunakan rumus 2.2 dan hasilnya dapat dilakukan dengan cara sebagai berikut:

Langkah pertama cara untuk mendapatkan kapasitas dasar (Co) telah dilakukan pada perhitungan sebelumnya.

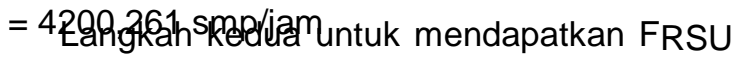
(Faktor Penyesuaian Tipe Lingkungan jalan, hambatan samping dan kendaraan tidak bermotor) yaitu dengan cara data Pum kita interpolasikan dan untuk data interpolasi bisa kita lihat pada tabel yang ada pada lampiran MKJI Bagian Jalinan Hal 4-34. Cara perhitungannya dapat dilakukan sebagai berikut:

\section{Kelas Hambatan Samping}

Dalam menentukan kelas hambatan samping ini dilakukan survey hambatan samping yang mana hasilnya sebagai berikut:
a). Pejalan kaki $=20 \times 0,5=10$
b). Kendaraan parkir/berhenti $=30 \times 1,00=30$
c). Kendaraan bergerak lambat $=155 \times 0,4=62$

Jumlah hambatan samping $=10+30+62=102$, sehingga termasuk dalam kelas hambatan samping rendah. 


\section{Perhitungan FRSU}

Perhitungannya FRSU dapat dilakukan seperti disajikan pada Tabel 2 .

Tabel 2. Perhitungan FRSU

\begin{tabular}{|c|c|c|c|c|c|c|c|}
\hline $\begin{array}{c}\text { Lingkungan } \\
\text { Jalan }\end{array}$ & $\begin{array}{c}\text { Hamba- } \\
\text { tan }\end{array}$ & 0.00 & 0.05 & 0.10 & 0.15 & 0.20 & $>0.25$ \\
\hline Komersil & rendah & 0.95 & 0.90 & 0.86 & 0.81 & 0.76 & 0.71 \\
$\begin{array}{c}\text { Pemukiman } \\
\text { Akses } \\
\text { terbatas }\end{array}$ & rendah & 0.98 & 0.93 & 0.88 & 0.83 & 0.78 & 0.74 \\
\hline
\end{tabular}

Sebagai Contoh Untuk komersil pada jam Puncak di pagi hari yang ada pada Tabel 4.15, terlihat nilai Pum yaitu 0,008 .

Cara Interpolasi sebagai berikut:

Nilai Pum masuk pada kategori 0,00-0,05 dan Weaving Area masuk pada daerah komersil, hambatan rendah yaitu 0,95-0,90. Kemudian masukan kedalam rumus interpolasi sebagai berikut:

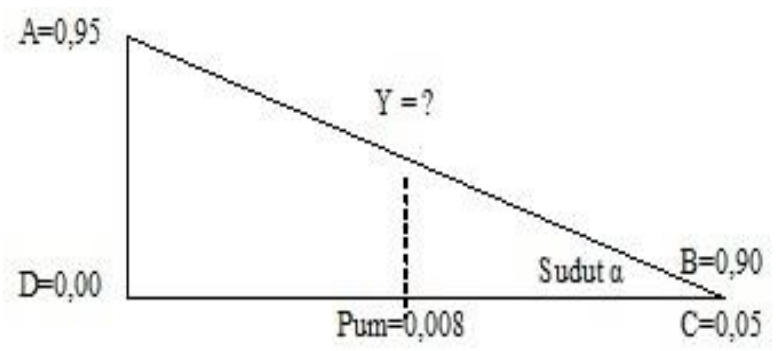

$\operatorname{Tg} \alpha=\frac{A \quad B}{C \quad D}=\frac{Y}{C \quad \text { Pum }}$

$Y=\frac{0,05}{0,05}=\frac{Y-0,90}{0,042} \quad Y=\frac{0,05}{0,05} \cdot 0,042+0.90$

$Y=0,042+0,90=0,942$

Langkah ketiga untuk mencari nilai FCS (Faktor Penyesuaian Ukuran Kota) dapat kita lihat dari jumlah penduduk Kota Palangka Raya yaitu sebesar 244.500 (dalam jumlah penduduk menurut jenis kelamin 2013). Untuk jumlah Kota Palangka Raya, masuk ke dalam urutan yang kecil yaitu 0,01-0,05 dengan angka FCS 0,088. Bisa dilihat pada lampiran tabel B-3:1 Faktor penyesuaian ukuran Kota pada lampiran 4-34.

Langkah keempat yaitu untuk mencari $C$ (Kapasitas), hasilnya dapat dilihat pada Tabel 3.

Tabel 3. Kapasitas sesungguhnya pada waktu jam puncak

\begin{tabular}{|c|c|c|c|c|}
\hline $\begin{array}{c}\text { Jam } \\
\text { puncak }\end{array}$ & $\begin{array}{c}\text { Co } \\
(\mathrm{smp} / \mathrm{jam})\end{array}$ & Fcs & F $_{\text {RSU }}$ & C (smp/jam) \\
\hline Pagi & 4200,261 & 0,88 & 0,942 & 3481,848 \\
\hline Siang & 4257,974 & 0,88 & 0.933 & 3495,967 \\
\hline Sore & 4316,787 & 0,88 & 0,946 & 3593,639 \\
\hline
\end{tabular}

\section{Perilaku Lalu Lintas pada Weaving Area Derajat Kejenuhan}

Derajat kejenuhan adalah nilai perbandingan antara arus lalu lintas jam puncak atau arus lalu lintas sesungguhnya dengan kapasitas sesungguhnya, seperti dalam rumus 2.4 hasil analisisnya dapat dilihat pada Tabel 4 .

Tabel 4. Derajat kejenuhan pada masing-masing jam puncak

\begin{tabular}{|c|c|c|c|}
\hline $\begin{array}{c}\text { Jam } \\
\text { Puncak }\end{array}$ & $\mathrm{Q}(\mathrm{smp} / \mathrm{jam})$ & $\mathrm{C}(\mathrm{smp} / \mathrm{jam})$ & $\mathrm{DS}=\mathrm{Q} / \mathrm{C}$ \\
\hline Pagi & 2420,07 & 3481,848 & 0,695 \\
\hline Siang & 2776,13 & 3495,967 & 0,692 \\
\hline Sore & 2337,17 & 3593,639 & 0,673 \\
\hline
\end{tabular}

\section{Tundaan Bagian Jalinan Bundaran (DT)}

Berdasarkan pada rumus 2.5 dan 2.6 dapat dianalisis perhitungan tundaan bagian jalinan sebagai berikut:

1) Tundaan bagian jalinan pada jam puncak pagi hari

$$
\begin{aligned}
& 1 /(0,59186-0,52525 \times 0,695)-(1-0,695) \times \\
& 2=3,799 \mathrm{det} / \mathrm{smp}
\end{aligned}
$$


2) Tundaan bagian jalinan pada jam puncak siang hari

$1 /(0,59186-0,52525 \times 0,692)-(1-0,692) x$

$2=3,766 \mathrm{det} / \mathrm{smp}$

3) Tundaan bagian jalinan pada jam puncak siang hari

$1 /(0,59186-0,52525 \times 0,673)-(1-0,673) x$

$2=3,546 \mathrm{det} / \mathrm{smp}$

\section{Peluang Antrian Bagian Jalinan (QP \%)}

Berdasarkan rumus 2.7 dan 2.8 dapat dianalisa perhitungan peluang antrian bagian jalinan, sehinnga dapat dihasilkan seperti pada Tabel 5.

Table 5. Peluang antrian bagian jalinan (QP \%) pada masing-masing jam puncak

\begin{tabular}{|c|c|c|c|}
\hline \multirow{2}{*}{$\begin{array}{c}\text { Jam } \\
\text { Puncak }\end{array}$} & \multirow{2}{*}{$\begin{array}{c}\text { Derajat } \\
\text { Kejenuhan } \\
\text { (DS) }\end{array}$} & \multicolumn{2}{|c|}{$\begin{array}{c}\text { Peluang antrian bagian } \\
\text { jalinan (QP\%) }\end{array}$} \\
\cline { 3 - 4 } & & Batas bawah & Batas atas \\
\hline Pagi & 0,695 & 12,12 & 28,18 \\
\hline Siang & 0,692 & 11,99 & 27,89 \\
\hline Sore & 0,673 & 11,16 & 25,95 \\
\hline
\end{tabular}

\section{KESIMPULAN DAN SARAN}

\section{Kesimpulan}

Berdasarkan analisis penelitian yang dilakukan pada daerah studi yakni Bundaran Besar Kota Palangka Raya dapat disimpulkan sebagai berikut:

1. Volume lalu lintas pada bagian jalinan (weaving section) bundaran besar Palangka Raya pada segmen jalan Yos SoedarsoKinibalu adalah sebagai berikut:

a) Volume lalu lintas harian rata-rata pada jam puncak pada waktu pagi hari didapat volume total $(\mathrm{QTOTAL})=2420,07 \mathrm{smp} / \mathrm{jam}$,
$\mathrm{QW}=1335,97 \mathrm{smp} / \mathrm{jam}$, dan $\mathrm{QNW}=$ 1084,1 smp/jam.

b) Volume lalu lintas harian rata-rata pada jam puncak pada waktu siang hari didapat volume total $($ QTOTAL $)=2776,13 \mathrm{smp} / \mathrm{jam}$, $\mathrm{QW}=1477,90 \mathrm{smp} / \mathrm{jam}$, dan $\mathrm{QNW}=$ 1298,23 smp/jam.

c) Volume lalu lintas harian rata-rata pada jam puncak pada waktu sore hari didapat volume total $($ QTOTAL) $=2337,17 \mathrm{smp} / \mathrm{jam}$, $\mathrm{QW}=1203,27$ smp/jam, dan QNW = 1133,9 smp/jam.

2. Kinerja bagian jalinan bundaran besar Palangka Raya pada segmen jalan Yos Soedarso-Kinibalu adalah sebagai berikut:

a) Pada Ialu lintas harian rata-rata pada jam puncak pagi hari di dapat kapasitas sesungguhnya $(C)=3481,848 \mathrm{smp} / \mathrm{jam}$, derajat kejenuhan $\mathrm{DS}=0,695$, tundaan bagian jalinan $(\mathrm{DT})=3,799 \mathrm{det} / \mathrm{smp}$, dan peluang antrian bagian jalinan ( $\mathrm{Qp} \%)=$ batas bawah/minimum sebesar $12,12 \%$, dan pada batas atas/maksimum sebesar $28,18 \%$.

b) Pada lalu lintas harian rata-rata pada jam puncak siang hari di dapat kapasitas sesungguhnya $(C)=3495,967 \mathrm{smp} / \mathrm{jam}$, derajat kejenuhan $\mathrm{DS}=0,692$, tundaan bagian jalinan $(\mathrm{DT})=3,766 \mathrm{det} / \mathrm{smp}$, dan peluang antrian bagian jalinan (Qp\%) = batas bawah/minimum sebesar $11,99 \%$, dan pada batas atas/maksimum sebesar $27,89 \%$.

c) Pada lalu lintas harian rata-rata pada jam puncak sore hari di dapat kapasitas sesungguhnya $(C)=3593,639 \mathrm{smp} / \mathrm{jam}$, derajat kejenuhan $\mathrm{DS}=0,673$, tundaan 
bagian jalinan $(\mathrm{DT})=3.546 \mathrm{det} / \mathrm{smp}$, dan peluang antrian bagian jalinan $(\mathrm{Qp} \%)=$ batas bawah/minimum sebesar $11,16 \%$, dan pada batas atas/maksimum sebesar $25,95 \%$.

Jadi dari masing-masing jam puncak yang terjadi pada bagian jalinan (weaving area) pada segmen jalan Yos Soedarso-Kinibalu masih memenuhi syarat derajat kejenuhan (DS) yang ditetapkan menurut MKJI 1997 yaitu, DS<0,75.

\section{Saran}

1. Untuk Jalinan Jalan (weaving area) dan Derajat Kejenuhan Kota Palangka Raya masih memenuhi syarat yang di sarankan MKJI, 1997, sehingga tidak perlu ada rencana desain ulang.

2. Perlu adanya penerangan pada weaving tersebut, sehingga para pengendara di malam hari bisa lebih merasa nyaman ketika melewati bundaran tersebut.

3. Apabila pada bagian jalinan jalan (weaving area) pada ruas jalan Yos Soedarso-Kinibalu di Bundaran Besar Palangka Raya itu terjadi titik jenuh yang maksimal/sangat jenuh maka harus diperlukan:

a) Memasang Rambu Lalu lintas Pada bagian jalinan tersebut

b) Memperlebar bagian jalinan dengan cara mengurangi pulau yang ada di tengah bundaran.

c) Memasang Lampu pengatur lalu lintas (traffic light) pada persimpangan tersebut.

\section{DAFTAR PUSTAKA}

Alamsyah Ansyori Alik, 2005, Rekayasa Lalu Lintas.

Anggoro Riant, 2013, Analisis Geometrik Bundaran Burung Kota Palangka Raya, Fakultas Teknik Universitas Muhammadiyah Palangka Raya.

Anonim, 1997, Manual Kapasitas Jalan Indonesia (MKJI), Republik Indonesia Dirjen Bina Marga, Direktorat Bina Jalan Kota (Binkot).

Anonim, 1997, Pedoman Perencanaan dan Pengoperasian Lalu Lintas di Wilayah PerKotaan, Rekayasa Lalu Lintas, Direktorat Bina Marga Sistem Lalu Lintas dan Angkutan Kota, Dirjen Perhubungan Darat.

Apriani Selpiana, dkk, 2013, Studi Persimpangan Bundaran Suci Kabupaten Garut,Jurnal Kontruksi Sekolah Tinggi Teknologi Garut.

Badan Pusat Statistik Kota Palangka Raya, 2014. Palangka Raya Dalam Angka Tahun 2014. BPS Kota Palangka Raya. Palangka Raya.

Direktorat Jenderal Bina Marga, (1997), Manual Kapasitas Jalan Indonesia. Jakarta.

Departemen Pemukiman dan Prasarana Wilayah, 2004, Perencanaan Bundaran untuk persimpangan sebidang.

Muchlisin, 2001, Analisis Kinerja Bundaran (Studi Kasus : Bundaran Samsat Yogyakarta, Fakultas Teknik Universitas Gajah Mada, Yogyakarta.

Sumina, 2011, Analisis Simpang Tak Bersinyal Dengan Bundaran (Studi Kasus Simpang Gladak Surakarta), Fakultas Teknik Universitas Tunas Pembangunan Surakarta.

Wells.R.G., 1993. Rekayasa Lalu Lintas, Terjemahan Ir. Suwardjoko warpani, Penerbit Bhratara, Jakarta 